\author{
J. O. Hamed ${ }^{1 *}$, O. O. Ogunleye ${ }^{2}$, C. A. Osheku ${ }^{1}$ \\ ${ }^{1}$ Center for Space Transport and Propulsion, NASRDA, Epe, Lagos \\ ${ }^{2}$ Department of Chemical Engineering, LAUTECH, Ogbomoso \\ *hamedjimoh45@yahoo.com
}

\title{
OPTIMAL DESIGN OF A COMPOSITE PROPELLANT FORMULATION USING RESPONSE SURFACE METHODOLOGY
}

\begin{abstract}
There is a continuous demand for high performance composite propellant formulations to meet mission requirements. The performance of composite propellant formulations can be enhanced by optimizing propellant formulation. However, the main objective of this study is to formulate a composition for composite propellant by optimizing the specific impulse which is the measure of propellant performance. A central composite design (ccd) consisting five ingredients (ammonium nitrate, powdered aluminum, polyester resin, ammonium dichromate and powdered charcoal) at five levels was used to formulate optimum propellant formulation from composite materials of ammonium nitrate based propellant verified for propellant characteristics using propellant performance evaluation programme (propep 3). The responses evaluated are specific impulse, characteristic velocity, density, temperature and molecular weight. Response surface methodology was used to analyze the results of the ccd of the composite formulations. The optimum values for specific impulse, characteristic velocity, density, temperature and molecular weight of the mixture from the surface plot are $212.178 \mathrm{~s}, 1335.81 \mathrm{~m} / \mathrm{s}, 1640.6 \mathrm{k} \mathrm{g} / \mathrm{m} 3,1968.73 \mathrm{k}$ and $21.7722 \mathrm{~g} / \mathrm{mol}$ respectively. The optimum predicted specific impulse was $212.178 \mathrm{~s}$ at composite composition of $73.61 \%$ ammonium nitrate, $4.36 \%$ powdered aluminum, $14.39 \%$ polyester resin, $5.10 \%$ ammonium dichromate and $2.54 \%$ powdered charcoal. The propellant optimum composition validated with propep 3 are in good agreement with each other in their accompany propellant characteristics. Therefore, the optimal propellant formulation enhanced the performance of solid propellants.
\end{abstract}

Keywords: specific impulse, characteristic velocity, composite propellant, polyester resin, ammonium bi-chromate

\section{INTRODUCTION}

In general, a typical composite propellant used in solid rocket motors consists of organic polymeric binder, solid oxidizer, powdered metal, curing agent, plasticizer, anti-oxidant and burning rate catalyst. Nowadays, composite propellants usually use additives to enhance their mechanical properties [1, 8]. A small amount of additives are used in composite propellants for many purposes, such as altering burning rate, improving physical properties, aging characteristics and rheology enhancement [2, 9]. Composite propellants of ammonium per-chlorate (AP) base are widely used nowadays. AP as oxidizer, powdered metals as fuels and some additives for curing purposes or burn rate modifiers [3]. These propellants are well known for good 
performance characteristics. Nevertheless, their limitations and liabilities regarding toxicity, operational handling and environmental impact are also well documented [4].

Consequently, continuous efforts are on for alternative oxidizer without compromising the composite characteristics. Therefore optimizing the composite formulation to enhance good performance becomes an essential issue. The need to apply process optimization as an essential tool demonstrated high efficiency in selecting optimal process variables in many chemical processes [13]. Among process optimization tools that have been effectively applied to chemical processes is response surface methodology (RSM) [7]. RSM is a collection of statistical and mathematical techniques for developing, improving and optimizing processes and new products, as well as in the improvement of existing product designs [14]. Also, Response surface methodology is a reliable tool for optimization of solid propellant grains design [15].

This study was based on a typical ammonium nitrate based solid composite propellant and the objective is to design an optimal propellant formulation by optimizing its specific impulse, characteristic velocity, density, temperature and molecular weight for better performance. The rocket fuel composed of ammonium nitrate (AN) as an oxidizer instead of ammonium perchlorate (AP), powdered aluminum (Al) as a metal fuel, polyester resin as a binder, ammonium bi-chromate as curing agent and powdered charcoal as opacifier [10,12]. Ammonium bi-chromate was used as a cross-linker to cure polyester resin and basically chosen because of its higher pot life [5]. However, replacing the AP with ammonium nitrate will also provide a good propellant performance with lower environmental impact [11]. The only drawback of ammonium nitrate based composite composition is low burn rate and powdered charcoal was used as an additive to keep the combustion steady [6]. Also, various combinations of chemical ingredients at different mixes result in divert physical and chemical properties as well as combustion characteristic and performance. This lead to erosive burning in most cases [23]. Hence, there is a need for a design of optimal formulation to enhance better propellant performance. The CCD tailored composition was verified using PROPEP 3 for different propellant properties such as specific impulse, characteristic velocity, density, temperature and molecular weight ratio. In the following section, the development of optimal formulation to enhance its performance using RSM was well documented.

\section{PROPELLANT INGREDIENTS}

Composite propellants are solid rocket fuels that composed of separate fuels and oxidizers mixed together with binder in one homogenous mass. This is then either molded into a grain to be inserted in an engine or cast in an engine casing and left to be hardening [2]. The fuels and oxidizers taken separately are generally un-reactive. The propellants are used in a number of engines such as space lunches, missile and gun [16]. Different chemical ingredients and their proportions result in different physical and chemical properties, combustion characteristics, and performance.

\section{Oxidizer}

The oxidizer may be a monopropellant and as such contributes power to the propellant mix. The ideal oxidizer should decompose into totally gaseous exhaust. Oxidizers used are potassium per-chlorate, ammonium per-chlorate, ammonium nitrate etc. Per-chlorate was one of the first 
oxidizers ever used [20]. One of its drawbacks is the product of decomposition (potassium chloride) is not a gas at regular temperatures and does not contribute as a working gas. The potassium chloride $(\mathrm{KCl})$ appears as a dense smoke in the rockets exhaust. Ammonium nitrate is useful as it is usually available in bulk weight. The products of its disassociation are $100 \%$ gas. However, the temperatures generated are very low [17].

Fuel

Metal fuel such as aluminum and boron are frequently added to propellant mixtures. Aluminum, one of the widely recognized metal additives, is used in the form of small spherical particles $(5-60 \mu \mathrm{m})$ in many varieties of solid propellants. Aluminum particles usually comprise $14-20 \%$ of the propellant weight. Addition of metal fuel enhances the heat of combustion, propellant density, combustion temperature, and hence the specific impulse [19].

\section{Binder}

Binders provide structural glue or matrix in which solid granular ingredients are held together in a composite propellant. The raw materials are liquid pre-polymers or monomers. This impacts the mechanical and chemical properties, propellant processing, and aging of the propellant. Binder materials typically act as a fuel, which gets oxidized in the combustion processes. Commonly used binders are HTPB, CTPB, and NC [18].

\section{Additives}

A small amount of additives such as curing agent, plasticizer, anti-oxidant, opacifier and burning rate catalyst are used in composite propellants for many purposes, such as altering burning rate, improving physical properties, aging characteristics and rheology enhancement $[1,2]$. Substances such as iron oxide increase the burning rate, lithium fluoride decreases the burning rate and powdered charcoal helps to keep the combustion steady [4]. These materials help to tailor the burning rate to fit the grain design and thrust-time requirements.

\section{MATERIALS AND EXPERIMENTAL DESIGN}

\section{Materials}

Ammoniums nitrate (AN), Polyester resin, Aluminum powder, Ammonium dichromate and powdered charcoals were considered as composite ingredients for design analysis using RSM. These materials compositions designed by CCD were used to verify propellant characteristics using PROPEP 3 at $101.325 \mathrm{MPa}$. The specific impulse (Isp) is the most important performance parameter. Generally, high Isp is required to obtain optimum performance [21]. In this paper, the simulated Isp was estimated using PROPEP 3 at $101.325 \mathrm{MPa}$, a computer programmme for rocket performance. This programme was also applied by several researchers to estimates the propellant performance characteristics [21,22]. According to the estimations, the Isp improves 
with the increasing of ammonium nitrate content and the best value is obtained at optimum mixture ratio.

\section{Experimental Design}

Central Composite Design (CCD) of RSM was used for the experimental design to optimize the composite propellant formulations. The CCD consists of five propellant ingredients considered as factors: ammonium nitrate from $58.33 \%$ to $76.58 \%$, powdered aluminum from $3.41 \%$ to $7.32 \%$, polyester resin from $14.01 \%$ to $25.00 \%$, ammonium bi-chromate from $3.37 \%$ to $7.57 \%$ and powdered charcoal from $1.26 \%$ to $3.36 \%$, and five level. The actual process variable is related to the coded process variables as shown on Table 1 according to equation (1).

Table 1. Experimental increments, values of coded levels

\begin{tabular}{|l|c|c|c|c|}
\hline \multirow{2}{*}{ Factors $\left(x_{i}\right)$} & \multirow{2}{*}{ \pm Increment } & \multicolumn{3}{|c|}{$X_{i}$ coded levels } \\
\cline { 3 - 5 } & & -1 & 0 & 1 \\
\hline$x_{1}$ & \pm 0.2 & 1.8664 & 2.3333 & 2.7996 \\
\hline$x_{2}$ & \pm 0.2 & 1.2000 & 1.5000 & 1.8000 \\
\hline$x_{3}$ & \pm 0.2 & 0.5712 & 0.7140 & 0.8568 \\
\hline$x_{4}$ & \pm 0.2 & 2.0000 & 2.5000 & 3.0000 \\
\hline \multicolumn{5}{|c}{$X_{i}=\frac{x_{i}-x_{0}}{\Delta x}$} \\
\end{tabular}

Where $X_{i}$ are the coded value of the independent variables, $x_{i}$ are the actual value of the independent variables at the design center point and $\Delta x$ is the variation increments about the center point. The centre point chosen for the design were $70 \%$ ammonium nitrate (A), $18 \%$ polyester resin (B), 5\% powdered aluminum (C), 5\% ammonium bi-chromate (D) and 2\% powdered charcoal $(\mathrm{E})$. The coded $X_{i}$ ratios for each formulation as per experimental design were translated into a possible propellant formulation. The ingredient compositions were obtained by systematic algebraic solutions for A, B, C, D and E in terms of actual $x_{i}$ ratios and a unit quantity of a propellant as given in equation (2) to (6). The composite compositions at various levels and the responses are given in Table 2 having analyzed by PROPEP 3 for different composite composition performance. Thirty runs were verified and the order of the result was fully randomized to reduce the effect of the unexplainable variability in the observed responses due to extraneous factor. 
Table 2. Composite design and responses

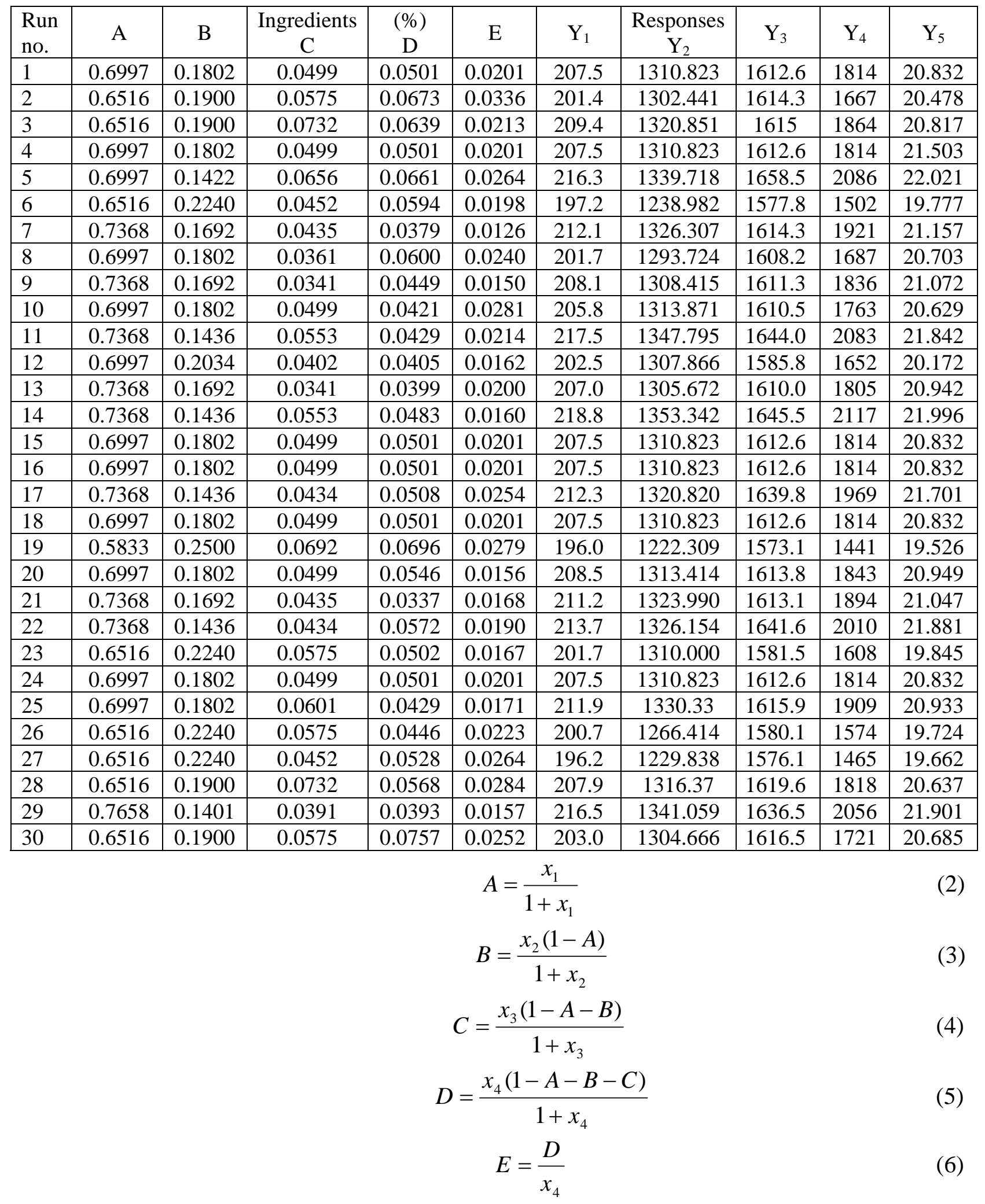




\section{Analysis of Data and Response Equations}

Regression models were developed for each of the five properties of composite propellant considered for this study as a function of the five ingredients used in the design. The DesignExpert 6.0 software was used to analyze the compositions for developing response equations, for analysis of variance (ANOVA), generate surface plots and determine optimum composite propellant formulation using its optimization toolbox. In multiple regressions, as in this case, $R^{2}$ is the square of the adjusted coefficient of determination and standard error are the indices. $F$ statistics shows the significance of the overall model while the $t$ statistics tests the significance of each of the variables of the model. The function was assumed to be approximated by a second order degree polynomial equation shown in equation (7).

$$
Y_{h}=b_{h_{o}}+\sum_{i=1}^{m} b_{h_{i}} X_{i}+\sum_{i=1}^{m} b_{h_{i i}} X^{2}{ }_{i}+\sum_{i \neq j=1}^{m} b_{h_{i j}} X_{i} X_{j}
$$

Where $b_{h_{0}}$ is the value of fitted response at the centre point of the design, i.e. $(0,0)$, and $b_{h_{i}}$, $b_{h_{i j}}$ and $b_{i j}$ are linear, quadratic and cross product regression term respectively. Also, $\mathrm{Y}$ is the propellant property and $\mathrm{m}$ is the number of composite ingredients considered which is equal to five in both cases for this study.

\section{Optimization and Validation}

A nonlinear programming problem of the form of equation (8) was formed from the vector of equation 7 as follows:

Maximise $Y_{1}=f\left(X_{i}\right)$,

Maximise $Y_{2}=f\left(X_{i}\right)$,

Minimize $Y_{3}=f\left(X_{i}\right)$,

Maximize $Y_{4}=f\left(X_{i}\right)$,

Maximize $Y_{5}=f\left(X_{i}\right)$.

Subject to:

$-1 \leq X_{i} \leq 1$

Where $X_{i}$ are composite propellant ingredient coded rations and $Y_{i}$ are composite propellants characteristics. This constrained maximization problem was solved using the Design-Expert 6.0 software. 


\section{RESULTS AND DISCUSSION}

\section{Performance Equation for Composite Formulation}

The effect of the CCD on the specific impulse $\left(\mathrm{Y}_{1}\right)$, the characteristic velocity $\left(\mathrm{Y}_{2}\right)$, density $\left(\mathrm{Y}_{3}\right)$, temperature $\left(\mathrm{Y}_{4}\right)$ and molecular weight $\left(\mathrm{Y}_{5}\right)$ is as shown on Table 2 that was subsequently used to fit the response equations for composite propellant properties. The factors of the models, the parameters and the statistics of the estimates for the best functions adopted, taking into consideration all main effects, linear, quadratic, and interaction for each model are as shown on Table 3. The coefficients of determination $\left(\mathrm{R}^{2}\right)$ for the five responses, specific impulse, characteristic velocity, density, temperature and molecular weight value were 0.9992, 0.9207, $0.9980,0.9997$ and 0.9565 respectively. The coefficients of determination were high for response surfaces, and indicated that the fitted quadratic models accounted for more than $92 \%$ of the variance in the experimental data. Base on $p$ values, the regression coefficient that was significant at $\mathrm{p}<95 \%$ were selected for the models that resulted in Equations (9) to (13). Analyses of variance (ANOVA) were conducted to evaluate the adequacy and consistency of the models using F- statistic. The analysis of variance of the models is presented in Table 4. As shown on the Table 4, the F- value for the specific impulse (1303.97), characteristic velocity (12.43), density (536.67), temperature (3154.14) and molecular weight value (137.27) were significant at $\mathrm{p}<0.05$ implying good model fit.

$$
\begin{gathered}
Y_{1}=163.6+19.0 x_{1}-20.5 x_{2}+51.6 x_{3}+4.7 x_{4}-1.4 x_{1}^{2}+5.3 x_{2}^{2}-8.7 x_{3}^{2}-3.2 x_{1} x_{3}-8.8 x_{2} x_{3} \\
R^{2}=0.9992 \\
Y_{2}=1339.8+194.8 x_{1}-372.4 x_{2}-23.3 x_{3}-34.5 x_{1}^{2}+51.5 x_{1} x_{2} \\
R^{2}=0.9207 \\
Y_{3}=1666.6+51.6 x_{1}-171.9 x_{2}+31.0 x_{3}-9.2 x_{1}^{2}+26.1 x_{2}^{2}+12.4 x_{1} x_{2} \\
R^{2}=0.9980 \\
Y_{4}=713.8+650.2 x_{1}-827.4 x_{2}+1261.4 x_{3}+164.1 x_{4}-76.2 x_{1}^{2}+150.5 x_{2}^{2}-206.4 x_{3}^{2} \\
-11.8 x_{4}^{2}+88.4 x_{1} x_{2}-106.9 x_{1} x_{3}-183.8 x_{2} x_{3}-19.2 x_{2} x_{4} \\
R^{2}=0.9997 \\
Y_{5}=19.3+1.3 x_{1}-1.5 x_{2}+0.2 x_{4} \\
R^{2}=0.9565
\end{gathered}
$$


Table 3. Estimated coefficients of the response models

\begin{tabular}{|c|c|c|c|c|}
\hline \multirow{2}{*}{ Specific impulse } & Model Factors & Coefficients & t-values & p-values \\
\hline & Constant & 207.50 & 163.58 & $0.0001 *$ \\
\hline & $\mathrm{X}_{1}$ & 5.17 & 19.04 & $0.0001 *$ \\
\hline \multirow[t]{10}{*}{$\left(\mathrm{Y}_{1}\right)$} & $\mathrm{X}_{2}$ & -3.23 & -20.47 & $0.0001 *$ \\
\hline & $\mathrm{X}_{3}$ & 2.53 & 51.59 & $0.0001 *$ \\
\hline & $\mathrm{X}_{4}$ & 0.63 & 4.68 & $0.0001 *$ \\
\hline & $\mathrm{X}_{1}{ }^{2}$ & -0.31 & -1.44 & 0.0001* \\
\hline & $\mathrm{X}_{2}^{2}$ & 0.47 & 5.25 & $0.0001^{*}$ \\
\hline & $\mathrm{X}_{3}{ }^{2}$ & -0.18 & -8.68 & $0.0016^{*}$ \\
\hline & $\mathrm{X}_{1} \mathrm{X}_{3}$ & -0.21 & -3.19 & $0.0032 *$ \\
\hline & $\mathrm{X}_{2} \mathrm{X}_{3}$ & -0.38 & -875 & $0.0001 *$ \\
\hline & & $\mathrm{R}^{2}=0.9992$ & & \\
\hline & Constant & 1310.82 & 1339.77 & $0.0001 *$ \\
\hline Characteristic & $\mathrm{X}_{1}$ & 23.35 & 194.77 & $0.0001 *$ \\
\hline Velocity & $\mathrm{X}_{2}$ & -14.44 & -372.44 & $0.0001 *$ \\
\hline \multirow[t]{5}{*}{$\left(\mathrm{Y}_{2}\right)$} & $\mathrm{X}_{3}$ & 12.55 & -23.26 & $0.0001 *$ \\
\hline & $\mathrm{X}_{1}^{2}$ & -7.52 & -34.54 & $0.0054^{*}$ \\
\hline & $\mathrm{X}_{1} \mathrm{X}_{2}$ & 7.21 & 51.51 & $0.0313^{*}$ \\
\hline & & $\mathrm{R}^{2}=0.9207$ & & \\
\hline & Constant & 1612.60 & 1666.62 & $0.0001 *$ \\
\hline Density & $\mathrm{X}_{1}$ & 15.23 & 51.57 & $0.0001 *$ \\
\hline \multirow[t]{8}{*}{$\left(\mathrm{Y}_{3}\right)$} & $\mathrm{X}_{2}$ & -17.40 & -171.88 & $0.0001 *$ \\
\hline & $\mathrm{X}_{3}$ & 1.71 & 30.96 & $0.0001 *$ \\
\hline & $\mathrm{X}_{1}^{2}$ & -1.99 & -9.15 & 0.0001* \\
\hline & $\mathrm{X}_{2}^{2}$ & 2.34 & 26.05 & 0.0001* \\
\hline & $\mathrm{X}_{1} \mathrm{X}_{2}$ & 1.73 & 12.37 & $0.0001 *$ \\
\hline & & $\mathrm{R}^{2}=0.9980$ & & \\
\hline & Constant & 1814.00 & 713.79 & $0.0001 *$ \\
\hline & $\mathrm{X}_{1}$ & 151.92 & 650.18 & $0.0001 *$ \\
\hline Temperature & $\mathrm{X}_{2}$ & -104.67 & -827.36 & 0.0001* \\
\hline \multirow[t]{12}{*}{$\left(\mathrm{Y}_{4}\right)$} & $\mathrm{X}_{3}$ & 56.17 & 1261.38 & 0.0001* \\
\hline & $\mathrm{X}_{4}$ & 19.33 & 164.08 & 0.0001* \\
\hline & $\mathrm{X}_{1}^{2}$ & -16.58 & -76.17 & 0.0001* \\
\hline & $\mathrm{X}_{2}^{2}$ & 13.54 & 150.46 & 0.0001* \\
\hline & $\mathrm{X}_{3}^{2}$ & -4.21 & -206.37 & $0.0002 *$ \\
\hline & $\mathrm{X}_{4}{ }^{2}$ & -2.96 & -11.83 & $0.0040 *$ \\
\hline & $\mathrm{X}_{1} \mathrm{X}_{2}$ & 12.37 & 88.41 & 0.0001* \\
\hline & $\mathrm{X}_{1} \mathrm{X}_{3}$ & -7.13 & -106.93 & $0.0001^{*}$ \\
\hline & $\mathrm{X}_{2} \mathrm{X}_{3}$ & -7.88 & -183.82 & 0.0001* \\
\hline & $\mathrm{X}_{2} \mathrm{X}_{4}$ & -2.88 & -19.17 & $0.0237 *$ \\
\hline & & $\mathrm{R}^{2}=0.9997$ & & \\
\hline & Constant & 20.86 & 19.31 & $0.0001 *$ \\
\hline Molecular weight & $\mathrm{X}_{1}$ & 0.62 & 1.32 & $0.0001 *$ \\
\hline \multirow[t]{3}{*}{$\left(\mathrm{Y}_{5}\right)$} & $\mathrm{X}_{2}$ & -0.44 & -1.46 & $0.0001 *$ \\
\hline & $\mathrm{X}_{4}$ & 0.077 & 0.15 & 0.0266 \\
\hline & & $\mathrm{R}^{2}=0.9565$ & & \\
\hline
\end{tabular}

$*$ Significant at $\mathrm{p}$ value $<0.05$ at $95 \%$ Confidence interval 
Table 4. Analysis of variance for composite properties

\begin{tabular}{|c|c|c|c|c|c|}
\hline Ballistic Properties & Source of Variation & Sum of Squares & Mean Squares & F-values & Adjusted $\mathrm{R}^{2}$ \\
\hline Specific & Regression & 1070.99 & 76.50 & 1303.97 & 0.9984 \\
\hline \multirow[t]{2}{*}{ Impulse } & Residual & 0.88 & 0.059 & & \\
\hline & Total & 1071.87 & & & \\
\hline Characteristic & Regression & 25654.86 & 1832.49 & 12.43 & 0.8466 \\
\hline \multirow[t]{2}{*}{ Velocity } & Residual & 2210.52 & 147.37 & & \\
\hline & Total & 27865.38 & & & \\
\hline \multirow[t]{3}{*}{ Density } & Regression & 13266.53 & 947.61 & 536.67 & 0.9961 \\
\hline & Residual & 26.49 & 1.77 & & \\
\hline & Total & 13293.01 & & & \\
\hline \multirow[t]{3}{*}{ Temperature } & Regression & $9.212 \mathrm{E}+005$ & 65798.80 & 3154.14 & 0.9993 \\
\hline & Residual & 312.92 & 20.86 & & \\
\hline & Total & $9.215 \mathrm{E}+005$ & & & \\
\hline Molecular & Regression & 13.90 & 3.47 & 132.27 & 0.9495 \\
\hline \multirow[t]{2}{*}{ Weight } & Residual & 0.63 & 0.025 & & \\
\hline & Total & 14.53 & & & \\
\hline
\end{tabular}

*Significant level at $\mathrm{p}<0.05$

Ammonium nitrate ratio $\left(\mathrm{x}_{1}\right)$ had quite high linear positive effects on density and characteristic velocity than it had on molecular weight, specific impulse value and temperature but had negative quadratic effect on all the properties except molecular weight. It had negative interaction effect with powdered aluminum ratio on specific impulse, positive interaction effect with polyester resin ratio on characteristic velocity, temperature and density values. Polyester resin $\left(\mathrm{x}_{2}\right)$ ratio had negative linear effects on all properties but much greater on density and characteristic velocity but had positive quadratic effect on specific impulse, temperature and density. It has interaction effect on all properties except on molecular weight value. Powdered aluminum ratio $\left(\mathrm{x}_{3}\right)$ had stronger positive linear effect on density value compared with specific impulse and temperature but negative linear effect on characteristic velocity value. It has interaction effect on specific impulse and density but no interaction effect on characteristic velocity, temperature and molecular weight. It has no linear and quadratic effect on molecular weight. Ammonium dichromate $\left(\mathrm{x}_{4}\right)$ had stronger positive linear effects on density than specific impulse and molecular weight values. It also had negative quadratic effect on only density and interaction effect with polyester resin ratio on only density value. The powdered charcoal ratio had no statistical significant effect on all responses.

\section{Optimization of Composite Formulation}

The models $\left(\mathrm{Y}_{1}, \mathrm{Y}_{2}, \mathrm{Y}_{3}, \mathrm{Y}_{4}\right.$ and $\left.\mathrm{Y}_{5}\right)$ were useful for indicating the direction in which to change the variables in order to maximize specific impulse, characteristic velocity, density and molecular weight values while minimizing temperature value. The multiple regression equations were solved using Design Expert 6.0. The optimum values obtained were as follows: $212.178 \mathrm{~s}$, $1335.81 \mathrm{~m} / \mathrm{s}, 1640.6 \mathrm{Kg} / \mathrm{m}^{3}, 1968.73 \mathrm{~K}$ and $21.7722 \mathrm{~g} / \mathrm{mol}$ for specific impulse, characteristic velocity, density, temperature and molecular weight value respectively. The coded levels (ingredient ratios) are within the experimental range and this indicated that the selected variables are valid for the selected variables. The regression equation was optimized to obtain the optimum conditions using Design Expert 6.0. The actual value obtained for optimum response were: 2.79, 1.20, 0.57 and 2.01 for ammonium nitrate, polyester resin, powdered aluminum and ammonium dichromate ratio respectively were used to calculate for optimum ingredient composition as 
73.61\%, $14.39 \%, 4.36 \%, 5.10 \%$ and $2.54 \%$ for ammonium nitrate, polyester resin, powdered aluminum, ammonium dichromate and powdered charcoal as composite propellant composition respectively.

a)

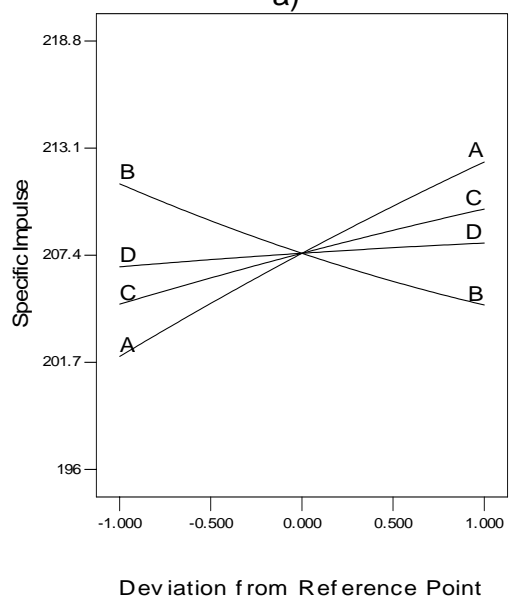

c)

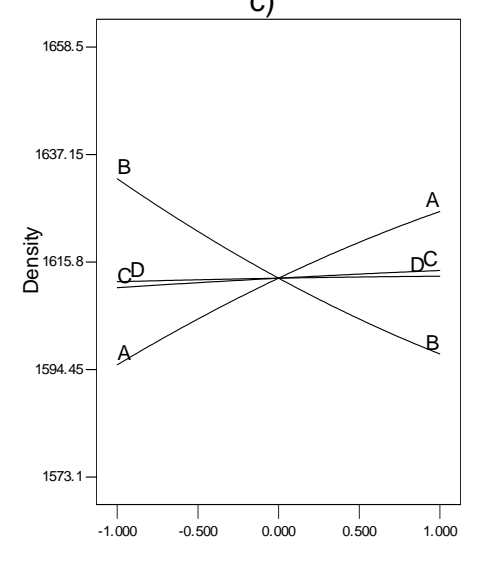

Deviation from Reference Point b)

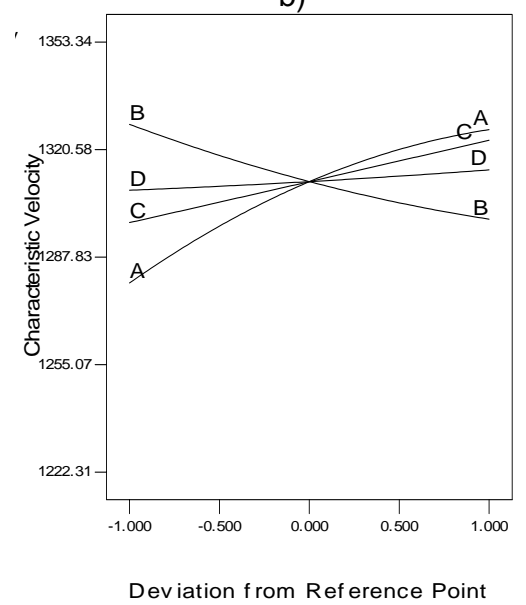

d)

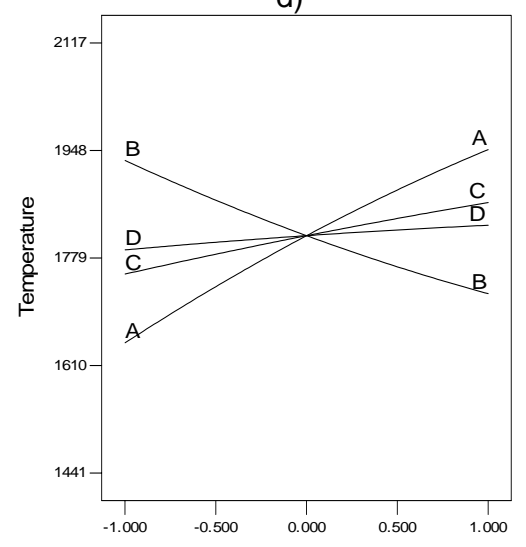

Deviation from Reference Point

e)

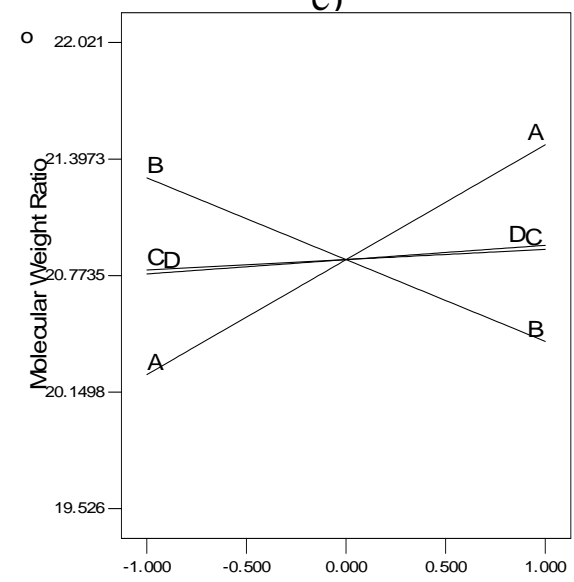

Deviation from Reference Point

Fig. 1. (a, b, c, d and e) are perturbaton plots showing interaction effects of ingredients ratio on propellant properties 
f)



h)



j)

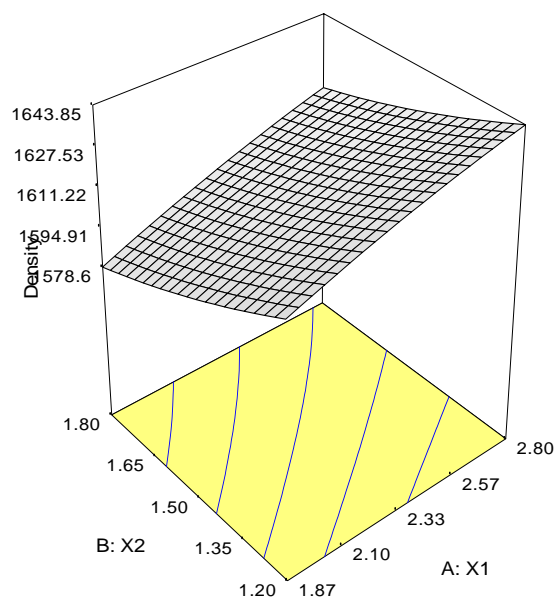

g)

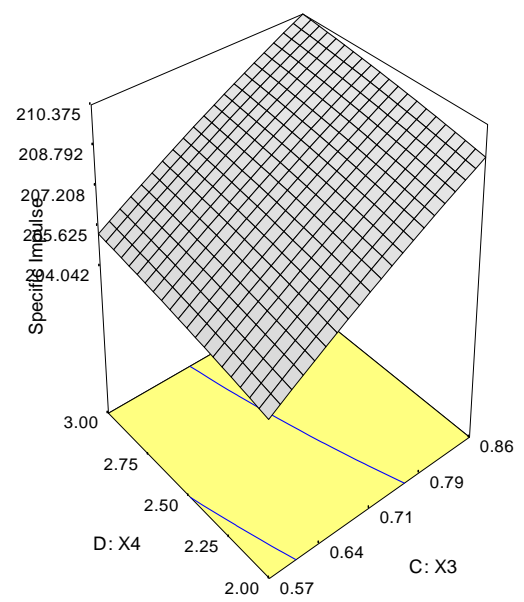

i)

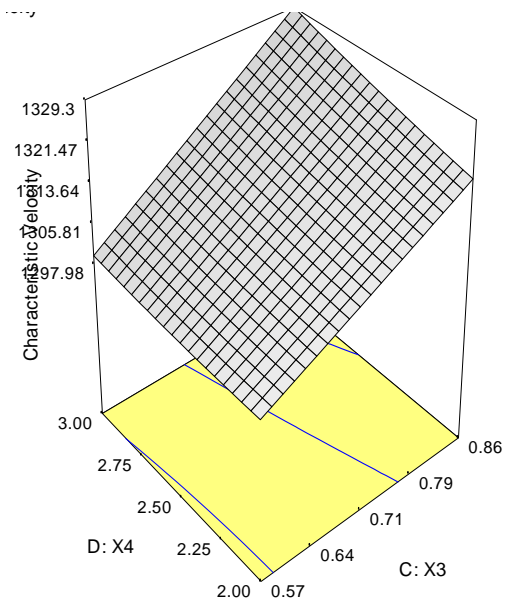

k)

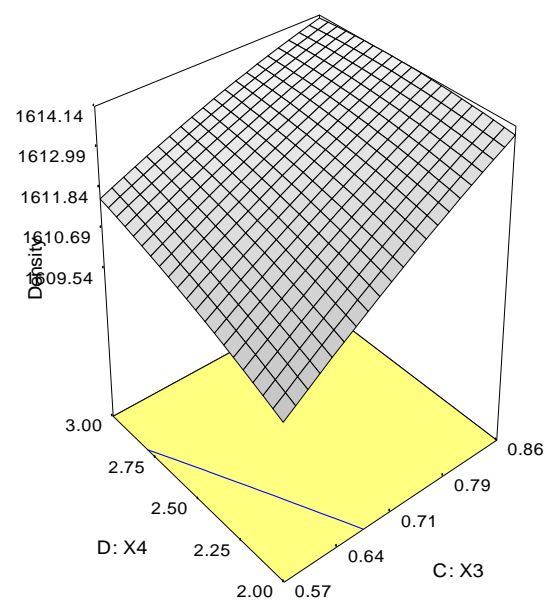


l)

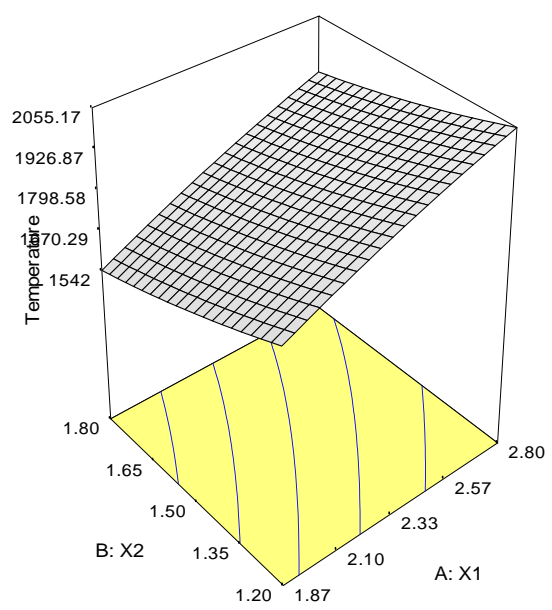

m)

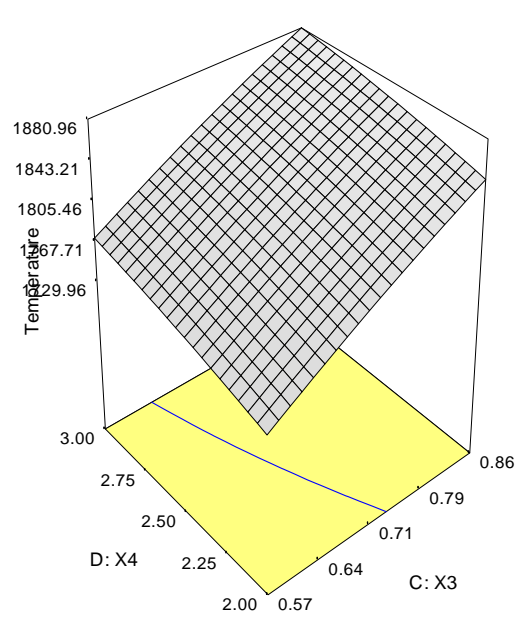

n)



Fig. 2. (f, $g, h, i, j, k, l, m$ and $n)$ are response surface plots showing interaction effects of ingredients ratio on propellant properties

The perturbation plots and response surface plots shown in Fig. 1 and Fig. 2 for the chosen model equations show the relationship between the independent and the dependent variables. From the figures, increase in all ingredient ratio brought increase in specific impulse and characteristic velocity except only polyester ratio which its increase lead to decrease in specific impulse and characteristic velocity until optimum point achieved for their interaction effect. Also, increase in ammonium nitrate ratio lead to corresponding increase propellant density, temperature and molecular weight mixture but the reverse is the case in polyester resin while changes in powdered aluminum and charcoal ratio had little or no effect on propellant density and molecular weight mixture but slightly increase with temperature until the optimum point achieved for composite interaction. 


\section{Validation of Composite Composition}

The ammonium nitrate based composite propellant designed is better interm of ballistic properties and efficiency when compared with sucrose based propellant of average specific impulse of $150 \mathrm{~s}$. Also, PROPEP 3 result was compared with the simulated result. The predicted specific impulse is $212.178 \mathrm{~s}$ and PROPEP specific impulse is $212.2 \mathrm{~s}$. The efficiency of 212.178 $\mathrm{s}$ in term of specific impulse of the developed composition in comparison with $207.6 \mathrm{~s}$ for the base composition is impressive. The results are in good agreement. This attests to the effectiveness of this framework for optimal design of composite propellant formulation.

\section{CONCLUSIONS}

A new propellants composition with a good performance with lower environmental effects, meeting the mechanical and ballistic properties has been successfully developed. This research establishes an optimization approach to determine the optimal formulation for composite propellant. Also, the mathematical models developed described the relationship between the ingredients and properties. The optimal composition may find application where such characteristics are needed to meet the ballistic mission requirement.

\section{ACKNOWLEDGEMENTS}

The authors gratefully acknowledged all colleagues at Centre for Space Transport and Propulsion, Epe, Lagos involved in the rocket fuel design and staff of Chemical Engineering department, Ladoke Akintola University of Technology, Ogbomoso for their moral support.

\section{REFERENCES}

1. Fitzgerald R. P., Brewster M. Q., Journal of Combustion and Flame, 154 (2008), 660-670p.

2. Carro R. et al., Proceedings of 41st AIAA/ASME/SAE/ASEE Joint Propulsion Conference and Exhibit Tucson, Arizona (2005).

3. Brown C. D., Spacecraft Propulsion, AIAA, Washington (1995).

4. Sutton G. P., Biblarz O., Rocket Propulsion Elements, John Wiley \& Sons, 7th ed., New York (2001).

5. Catherine K. B., et al., Journal of Thermal Analysis and Calorimetry, 59 (2000), 93-100.

6. Yang R., An H., Tan H., Combustion and Thermal Decomposition of HNIW and HTPB/HNIW Propellants with Additives, Combustion and Flame, 135 (2003), 463-473.

7. Singh S., Raina C. S., Bawa A. S., Sexena D. C., Sweet potato-based pasta product: optimization of ingredient levels using response surface methodology, International Journal of Food Science and Technology 38 (2003), 1-10. 
8. Langlet A., Wingborg N., Ostmark H., A New High Performance Oxidizer for Solid Propellants, International Journal of Energetic Materials and Chemical Propulsion, 4 (1997), 1-6.

9. Schoyer H. F. R., Schnork A. J., Korting P. A. O. G., van Lit P. J. First Experimental Results of an HNF/Al/GAP Solid Propellant, AIAA/ASME/SAE/ASEE Joint Propulsion Conference and Exhibit, T. L. 33rd, Seattle, WA, (1997) 6-9.

10.Couturier R., Advanced Energetic Binder Propellants, Solid Rocket Propulsion Technology, A. Davenas, Ed., Pergamon Press, Oxford, (1993) 510-511.

11.Boyars C., Klager K., Propellants, Manufacturing, Hazards and Testing, American Chemical Society, Washington D.C, 88 (1969).

12.Muthiah R. M., Varghese Rao S. S., Ninan K. N., Krishnamurthy V. N., Realization of an Eco-friendly Solid Propellant Based on HTPB-HMX-AP System for Launch Vehicle Applications, International Journal of Energetic Materials and Chemical Propulsion, 4 (1997), 1-6.

13.Hartfield R., Jenkins R., Burkhalter J., Foster W., A Review of Analytical Methods for Solid Rocket Motor Grain Analysis, AIAA (2003) 2003-4506.

14.Montgomery D. C., Design and Analysis of Experiments: Response Surface Method and Designs, New Jersey: John Wiley and Sons, Inc (2005).

15.Ogunleye O. O., Hamed J. O., Alagbe S. O., Optimization of Potassium Nitrate Based Solid Propellant Grains Design Using Response Surface Methodology, Advances in Science and Technology Research Journal, 9, No. 27 (2015), 123 - 134.

16.Sutton G. P., Rocket Propulsion Elements, John Wiley \& Sons, MIT, 6th ed., New York (1992).

17.Bluestone S., et al., Proceedings of 46th AIAA/ASME/SAE/ASEE Joint Propulsion Conference and Exhibit Nashville, TN (2010).

18.Cai W.D., Thakre P., Yang V., Model of AP/HTPB composite propellant combustion in rocket motor environments, Combust. Sci. Tech., 180 (2008), 2143-2169.

19.Yang V., Brill T., Ren W. Z., Solid-Propellant Chemistry, Combustion, and Motor Interior Ballistics, Progress Astronautics and Aeronautics, AIAA, 185 (2000), 990.

20.Beckstead M. W., Puduppakkam K., Thakre P., Yang V., Modeling of combustion and ignition of solid-propellant ingredients, Programme Energy Combustion Science, 33 (6) (2007), 497-551.

21.Krishnan S., Rajesh K. K., Proceedings of 37th AIAA/ASME/SAE/ASEE, Joint Propulsion Committee Conference and Exhibit Salt Lake City, Utah (2001).

22.Jayaraman K., et al., Combustion and Flame, 156 (2009), 1662-1673.

23. Yildirim C., Analysis of Grain Burn back and Internal Flow In Solid Propellant Rocket Motors in 3Dimensions, Ph. D. Dissertation, Department of Mechanical Engineering, METU, (2007), 110-118. 